\title{
\begin{tabular}{l|l} 
Mitraries & DSpace@MIT
\end{tabular}
}

\author{
MIT Open Access Articles
}

\section{Asymmetric Cu-Catalyzed 1,4-Dearomatization of Pyridines and Pyridazines without Preactivation of the Heterocycle or Nucleophile}

The MIT Faculty has made this article openly available. Please share how this access benefits you. Your story matters.

Citation: Gribble, Michael W., Jr., Sheng Guo, and Stephen L. Buchwald. "Asymmetric CuCatalyzed 1,4-Dearomatization of Pyridines and Pyridazines without Preactivation of the Heterocycle or Nucleophile." Journal of the American Chemical Society 140, 15 (Apr. 2018): p. 5057-60 doi 10.1021/JACS.8B02568 (c)2018 Author(s)

As Published: 10.1021/JACS.8B02568

Publisher: American Chemical Society (ACS)

Persistent URL: https://hdl.handle.net/1721.1/126089

Version: Author's final manuscript: final author's manuscript post peer review, without publisher's formatting or copy editing

Terms of Use: Article is made available in accordance with the publisher's policy and may be subject to US copyright law. Please refer to the publisher's site for terms of use. 


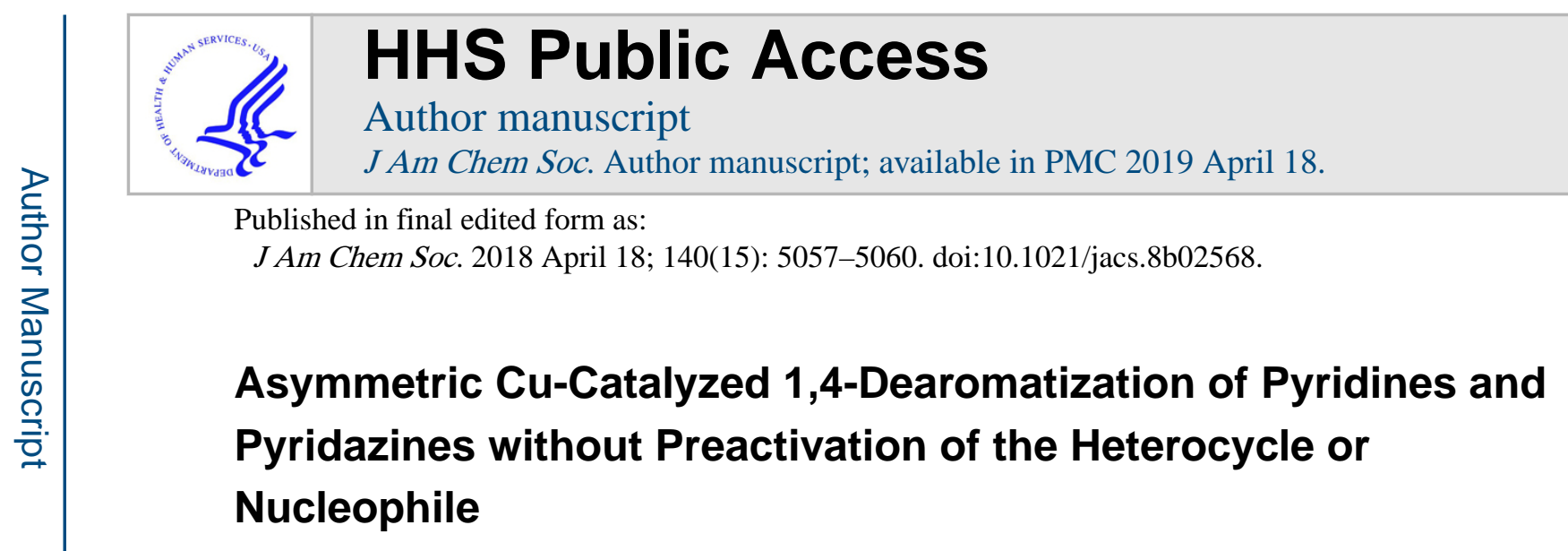

\author{
Michael W. Gribble Jr${ }^{\dagger}$, Sheng Guo ${ }^{\dagger}$, and Stephen L. Buchwald \\ Department of Chemistry, Massachusetts Institute of Technology, Cambridge, Massachusetts \\ 02139, United States
}

\begin{abstract}
We show that a chiral copper hydride $(\mathrm{CuH})$ complex catalyzes $\mathrm{C}-\mathrm{C}$ bond-forming dearomatization of pyridines and pyridazines at room temperature. The catalytic reaction operates directly on free heterocycles and generates the nucleophiles in situ, eliminating the need for stoichiometric preactivation of either reaction partner; further, it is one of very few methods available for the enantioselective 1,4-dearomatization of heteroarenes. Combining the dearomatization with facile derivatization steps enables one-pot syntheses of enantioenriched pyridines and piperidines.
\end{abstract}

\title{
Graphical abstract
}

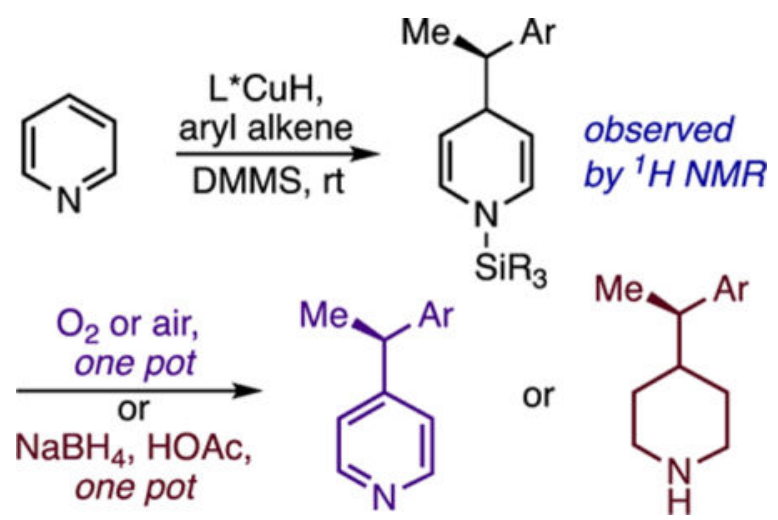

Dearomatization of electron-deficient heteroarenes with carbon nucleophiles is an essential transformation for the synthesis of pyridines and piperidines, which are the two most

\footnotetext{
${ }^{*}$ Corresponding Author: sbuchwal@mit.edu.

$\dagger$ Author Contribution

These authors contributed equally.

Supporting Information. The supporting Information is available free of charge on the ACS Publications website. Experimental procedures and characterization data for all compounds (PDF, CIF)

PDF

CIF

Notes

No competing financial interests have been declared
} 
common azaheterocycles in FDA-approved small-molecule drugs. ${ }^{1,2 \mathrm{a}-2 \mathrm{e}}$ However, direct dearomative addition to pyridine generally requires harsh conditions ${ }^{2 c, 3 b}$ and has limited compatibility with complex, functionalized molecules. Most $\mathrm{C}-\mathrm{C}$ bond-forming pyridine dearomatizations employ activated substrates generated through stoichiometric functionalization of the heterocyclic nitrogen with strong electrophiles. ${ }^{2-7}$ While useful, this approach has a number of limitations. For instance, many methods require pre-synthesis of the activated heterocycle ${ }^{2 \mathrm{c}}$ or prior formation of the nucleophile, and separate deprotection steps are commonly required to cleave the activating group from the dihydropyridine (DHP) product. Further, whereas numerous methods exist for asymmetric 1,2-dearomatization, ${ }^{4 a-4 e}$ achieving stereocontrol in 1,4-selective variants has proven much more challenging. The latter transformation is seldom possible without auxiliaries or pre-formed chiral nucleophiles (Figure 1, A and B); 5 ,6a-6c asymmetric catalysis of pyridine 1,4-dearomatization ${ }^{7 \mathrm{a}-7 \mathrm{~d}}$ was unknown until very recently, $2 \mathrm{c}$ and highly enantioselective catalytic reactions (Figure 1, C) $)^{7 b-7 d}$ are currently only possible with a narrow set of multiply activated cationic substrates. A number of catalyzed additions of hydride or silyl nucleophiles have been reported that operate directly on pyridine rather than on stoichiometrically activated derivatives, ${ }^{8 \mathrm{a}-8 \mathrm{j}}$ but there are no reactions of this type that achieve either $\mathrm{C}-\mathrm{C}$ bondformation or asymmetric induction. In this communication, we show that a chiral copper complex catalyzes $\mathrm{C}-\mathrm{C}$ bond-forming dearomatization under mild conditions without requiring activation of the heterocycle, pre-formation of the nucleophile, or protecting group manipulations (Figure 1, D). Moreover, the reaction is a very rare example of highly enantioselective catalytic 1,4-dearomatization, it succeeds with a broad selection of substituted pyridines and pyridazines, and it generates DHPs that can be converted to enantioenriched pyridines or piperidines in the same pot.

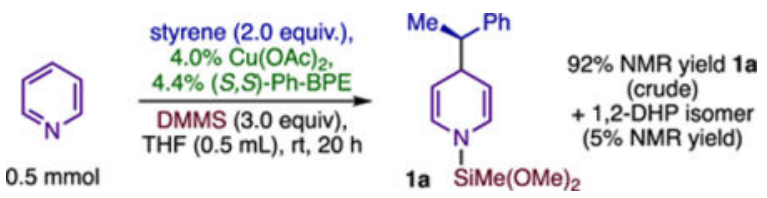

We hypothesized that pyridine could be activated toward nucleophilic dearomatization in an asymmetric hydrofunctionalization reaction, ${ }^{9,10}$ thereby permitting direct dearomatization of the heterocycle while replacing pre-formed nucleophiles with abundant olefin precursors. Subjecting a mixture of pyridine and styrene to ( $\mathrm{Ph}-\mathrm{BPE}) \mathrm{CuH}$, prepared as before (eq 1), 11,12 gave $97 \%$ conversion $\left({ }^{1} \mathrm{H}\right.$ NMR) to a mixture of dihydropyridines strongly biased in favor of the 1,4-adduct 1a (22:1 average 1,4:1,2). Treating crude DHPs with $\mathrm{O}_{2}{ }^{3 \mathrm{c}}$ provided efficient rearomatization and enabled a one-pot synthesis of functionalized pyridines (generically, 3; Table 1, A). Chiral analysis of pyridine 3a (90\% ee) indicated that the dearomatization had occurred with high enantioselectivity and that the aerobic rearomatization was stereospecific. ${ }^{13}$ Applying the dearomatization to the synthesis of enantioenriched piperidines also proved to be straightforward: adding $\mathrm{NaHB}(\mathrm{OAc})_{3}$ to crude DHPs provided good yields of piperidines (generically, 4; Table 1, B) in a one-pot 
operation ${ }^{14}$ that could be conducted on gram-scale without appreciable loss of yield or selectivity (4p; Table 1, B).

The dearomatization/reoxidation protocol succeeded with pyridines, pyridazines, and a variety of C3-substituted derivatives thereof. The enantioselectivity obtained with pyridazines (3g-k; Table 1, A) was consistently excellent and insensitive to the presence of electron-donor groups; in contrast, the ee's obtained with pyridines were moderately depressed by electron-releasing groups (e.g., 3d; Table 1, A) and enhanced by aryl and $\pi$ acceptor substituents (3e, 4s-u; Table 1, A and B). Substituted pyridines were also viable substrates for dearomatization/reduction, and stereochemical analysis of products $4 \mathbf{s}-\mathbf{u}$ (Table 1, B) revealed that both transformations exert control over the endocyclic stereocenters they respectively generate, leading to mixtures of diastereomeric piperidines having a major bias for the $\mathbf{4}$ (a,s) diastereomers [see inset in Table 1, B for explanation of nomenclature]. The major diastereomers were isolable in stereochemically pure form, and thus the dearomatization/reduction protocol enabled selective preparation of piperidines containing three contiguous stereocenters starting from prochiral substrates. Our work with this series provided key insights into the stereochemical properties of the asymmetric dearomatization. Single-crystal X-ray diffraction analysis of $\mathbf{4 s}(\mathbf{a}, \mathbf{s}) \cdot \mathbf{H C l}$ revealed its absolute configuration, ${ }^{15,16}$ making it clear that dearomative addition is retentive with respect to the benzylic stereocenter set during hydrocupration and selective for $(\mathrm{C} a, \mathrm{C} 4)$-anti DHPs, whereas the reduction is selective for $(\mathrm{C} 3, \mathrm{C} 4)$-syn piperidines. The basis for antiselective dearomative addition is unclear at present, but it appears to be general. ${ }^{15,17}$ Notably, retention of the phenethylcopper stereocenter contrasts with the clean inversion Aggarwal observed in the addition of chiral phenethylboronates to acylpyridiniums (Figure $1, \mathrm{~B}) ;{ }^{5}$ our result is mechanistically interesting given that the organocopper nucleophiles involved here do undergo invertive addition in other transformations. ${ }^{12 \mathrm{c}}$

Unlike C3 substituents, groups at $\mathrm{C} 4$ are only accommodated in special cases (as in $\mathbf{4 r}$; Table 1, B), and substitution at $\mathrm{C} 2$ is not tolerated even for substituents that increase the intrinsic electrophilicity of the free heterocycle (e.g., $\mathrm{CF}_{3}, \mathrm{CO}_{2} \mathrm{Me}$ ). Further, examples 3i-k (Table 1, A) show that organocopper nucleophiles preferentially add para to the less hindered nitrogen even when this entails attack on the more encumbered and more electronrich of the two activated sites. These observations concerning $\mathrm{C} 2$ substitution can be readily rationalized if one invokes coordination of the heterocycle to a sterically demanding Lewis acid (e.g., $\mathrm{Cu}$ ) in the dearomative addition step.

The dearomatization is compatible with various aryl alkene substituents, but certain trends involving this reactant were very surprising. Dearomatization exhibits useful levels of selectivity for a variety of olefin $\beta$ substituents ( $\mathbf{3 b}, \mathbf{3 k}, \mathbf{4 q}$; Table $1, \mathrm{~A}$ and $\mathrm{B}$ ), and ortho substitution is broadly tolerated (3c, $4 \mathbf{l}-\mathbf{n}$; Table 1 , A and B). But surprisingly, when groups such as F, Me and OMe are present at the para position of the styrene, they completely suppress dearomatization. This observation runs counter to all our previous experience with styrene hydrofunctionalization ${ }^{12 \mathrm{a}-12 \mathrm{e}}$ and leads us to propose that para substituents incur a destabilizing interaction unique to the dearomative addition transition state. Consistent with this, we observed some sensitivity to the steric demand of the meta substituent; thus, 3- 
methylstyrene is problematic for pyridine but not pyridazine $(\mathbf{3 g}, \mathbf{3 h}$; Table 1$)$, while metahalides are tolerated with both $(\mathbf{3 g}, \mathbf{3 i}$, $\mathbf{4 o - p}$; Table 1 , A and B).

Figure 2 illustrates one plausible mechanism for the $\mathrm{Cu}$-catalyzed direct dearomatization. Activation of the heterocycle occurs through formation of dative complex I (step i), which undergoes dearomatization with an organocopper nucleophile (II) (step iii). ${ }^{12 \mathrm{a}, 18}$ The resulting N-cuprated DHP intermediate (III) could then furnish product IV and the regenerated catalyst via $\sigma$-bond metathesis with the silane (step $i v$ ), similarly to transmetalation processes implicated in other catalytic hydrofunctionalizations. ${ }^{12,18-19} \mathrm{We}$ are currently undertaking a detailed mechanistic investigation directed at elucidating how activation and addition occur in this reaction.

In summary, we have demonstrated that pyridine and pyridazine undergo direct asymmetric dearomatization in the presence of a chiral $\mathrm{CuH}$ catalyst. This unique reaction eliminates the need for extraneous activation and nucleophile-formation steps, and it permits one-pot syntheses of highly enantioenriched C4-functionalized heterocycles. We expect that our ongoing mechanistic investigations will shed light on the unusual reactivity trends we observe and aid in the discovery of more general dearomative transformations.

\section{Supplementary Material}

Refer to Web version on PubMed Central for supplementary material.

\section{Acknowledgments}

The National Institutes of Health under award numbers GM46059 and R35-GM122483 supported research reported in this publication. We thank Richard Liu and Andy Thomas (MIT) for advice on the preparation of this manuscript, Charlene Tsay (MIT) for X-ray crystallographic analysis, Bruce Adams (MIT) for assistance with NMR structuredetermination, and the National Institutes of Health for a supplemental grant for the purchase of supercritical fluid chromatography (SFC) equipment (GM058160-17S1).

\section{References}

1. Vitaku E, Smith DT, Njardson JT. J Med Chem. 2014; 57:10257-10274. [PubMed: 25255204]

2. For reviews on pyridine dearomatization and dihydropyridine chemistry, see:(a) Lavilla R. J Chem Soc, Perkin Trans. 2002; 1:1141-1156.(b) Ahamed M, Todd MH. Eur J Org Chem. 2010; 2010:5935-5942.(c) Bull JA, Mousseau JJ, Pelletier G, Charette AB. Chem Rev. 2012; 112:26422713. [PubMed: 22352938] (d) Zhuo CX, Zhang W, You SL. Angew Chem, Int Ed. 2012; 51:12662-12686.(e) Ding Q, Zhou X, Fan R. Org Biomol Chem. 2014; 12:4807-4815. [PubMed: 24875150]

3. For examples of 1,4-dearomatizations using copper, see:(a) Piers E, Soucy M. Can J Chem. 1974; 52:3563-3564.(b) Comins DL, Abdullah AH. J Org Chem. 1982; 47:4315-4319.(c) Akiba KY, Iseki Y, Wada M. Bull Chem Soc Jpn. 1984; 57:1994-1999.

4. For examples of asymmetric catalysis using activated substrates, see:(a) Sun Z, Yu S, Ding Z, Ma D. J Am Chem Soc. 2007; 129:9300-9301. [PubMed: 17625864] (b) Black DA, Beveridge RE, Arndtsen BA. J Org Chem. 2008; 73:1906-1910. [PubMed: 18215063] (c) Fernández-Ibáñez MA, Maciá B, Pizzuti MG, Minnaard AJ, Feringa BL. Angew Chem, Int Ed. 2009; 48:9339-9341.(d) Lutz JP, Chau ST, Doyle AG. Chem Sci. 2016; 7:4105-4109. [PubMed: 28058106]

5. Mohiti M, Rampalakos C, Feeney K, Leonori D, Aggarwal VK. Chem Sci. 2014; 5:602-607.

6. For representative examples, see:(a) Meyers AI, Natale NR, Wettlaufer DG, Rafii S, Clardy J. Tetrahedron Lett. 1981; 22:5123-5126.(b) Mangeney P, Gosmini R, Raussou S, Commerçon M, 
Alexakis A. J Org Chem. 1994; 59:1877-1888.(c) Yamada S, Morita C. J Am Chem Soc. 2002; 124:8184-8185. [PubMed: 12105887]

7. (a) Mancheño OG, Asmus S, Zurro M, Fischer T. Angew Chem, Int Ed. 2015; 54:8823-8827.(b) Bertuzzi G, Sinisi A, Caruana L, Mazzanti A, Fochi M, Bernardi L. ACS Catal. 2016; 6:6473-6477. (c) Bertuzzi G, Sinisi A, Pecorari D, Caruana L, Mazzanti A, Bernardi L, Fochi M. Org Lett. 2017; 19:834-837. [PubMed: 28128963] (d) Flanigan DM, Rovis T. Chem Sci. 2017; 8:6566-6569. [PubMed: 28989683]

8. (a) Oshima K, Ohmura T, Suginome M. J Am Chem Soc. 2011; 133:7324-7327. [PubMed: 21510608] (b) Gutsulyak DV, van der Est A, Nikonov GI. Angew Chem, Int Ed. 2011; 50:13841387.(c) Hill MS, Kociok-Köhn G, MacDougall DJ, Mahon MF, Weetman C. Dalton Trans. 2011; 40:12500-12509. [PubMed: 21986998] (d) Königs CDF, Klare HFT, Oestreich M. Angew Chem, Int Ed. 2013; 52:10076-10079.(e) Dudnik AS, Weidner VL, Motta A, Delferro M, Marks TJ. Nat Chem. 2014; 6:1100-1107. [PubMed: 25411889] (f) Gandhamsetty N, Park S, Chang S. J Am Chem Soc. 2015; 137:15176-15184. [PubMed: 26580152] (g) Intemann J, Bauer H, Pahl J, Maron L, Harder S. Chem - Eur J. 2015; 21:11452-11461. [PubMed: 26120024] (h) Fan X, Zheng J, Li ZH, Wang H. J Am Chem Soc. 2015; 137:4916-4919. [PubMed: 25846625] (i) Kaithal A, Chatterjee B, Gunanathan C. Org Lett. 2016; 18:3402-3405. [PubMed: 27351256] (j) Zhang F, Song H, Zhuang X, Tung CH, Wang W. J Am Chem Soc. 2017; 139:17775-17778. [PubMed: 29192777]

9. Kanai has suggested that hydrometallation and dearomative addition steps occur in the mechanism of Co-catalyzed C-H functionalization of pyridine, although they do not describe observing the DHP; rather, they suggest that (presumably fast) rearomatization is intrinsic to the catalytic cycle.Andou T, Saga Y, Komai H, Matsunaga S, Kanai M. Angew Chem, Int Ed. 2013; 52:32133216.

10. After our work was completed, a paper appeared by Yu, et al. showing that phenethylcopper species generated in asymmetric hydrocupration effect reductive ortho $\mathrm{C}$-H-functionalization of quinoline N-oxides, probably via an initially dearomative mechanism. Yu S, Sang HL, Ge S. Angew Chem, Int Ed. 2017; 56:15896-15900.

11. For detailed information about the safe handling of dimethoxy(methyl)silane (DMMS), see the Supporting Information.

12. See, e.g.,(a) Bandar JS, Pirnot MT, Buchwald SL. J Am Chem Soc. 2015; 137:14812-14818. [PubMed: 26522837] (b) Wang YM, Buchwald SL. J Am Chem Soc. 2016; 138:5024-5027. [PubMed: 27042864] (c) Yang Y, Perry IB, Buchwald SL. J Am Chem Soc. 2016; 138:9787-9790. [PubMed: 27454393] (d) Gribble MW Jr, Pirnot MT, Bandar JS, Liu RY, Buchwald SL. J Am Chem Soc. 2017; 139:2192-2195. [PubMed: 28117996] (e) Zhou Y, Bandar JS, Buchwald SL. J Am Chem Soc. 2017; 139:8126-8129. [PubMed: 28565905]

13. The rearomatization causes some degradation of the DHPs through a pathway that regenerates some of the starting heterocycle - probably fragmentation of benzyl radical from a dihydropyridine radical cation. See the mechanism described inLudvík J, Volke J, Klíma J. Electrochim Acta. 1987; 32:1063-1071.

14. The reduction step is similar to that inSuryavanshi PA, Sridharan V, Maiti S, Menéndez JC. Chem - Eur J. 2014; 20:8791-8799. [PubMed: 24909665]

15. See supporting information for details.

16. The (a,s) Relative stereochemistry of products $4 \mathrm{t}$ and $4 \mathrm{u}$ was confirmed through NMR-based structure-determination. See SI.

17. For examples s-u, ${ }^{1} \mathrm{H}$ NMR assignments of anti-1 and syn-1 were possible using the known dr's for $4 \mathrm{~s}-\mathrm{u}$. Assignments made by analogy to these indicated that anti-1 was also major for every other DHP we analyzed by ${ }^{1} \mathrm{H}$ NMR. (NMR estimates for the dr are 25:1 for $1 \mathrm{~d}, 13: 1$ for $1 \mathrm{k}, 11: 1$ for $1 \mathrm{~s}$, 7:1 for $1 \mathrm{t}, 4.6: 1$ for $1 \mathrm{u}$; Table $1 \mathrm{~A}$ and B.) See the supporting information for details.

18. Xi Y, Hartwig JF. J Am Chem Soc. 2017; 139:12758-12772. [PubMed: 28787137]

19. See entry 19 on page $S 4$ of the supporting information for reference ${ }^{12 c}$. 

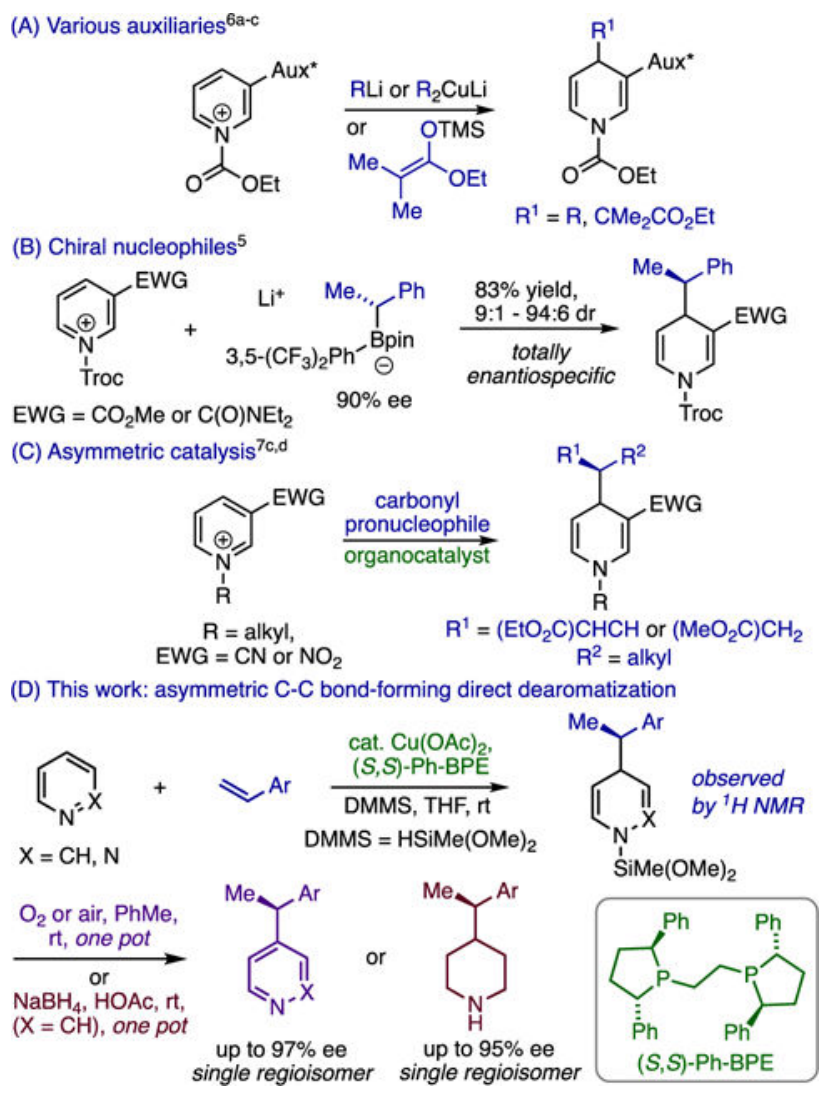

Figure 1.

Methods for stereocontrolled 1,4-dearomatization; (A) with chiral auxiliaries; (B) with chiral nucleophiles; (C) using asymmetric catalysis; (D) this work: asymmetric direct catalytic dearomatization. 


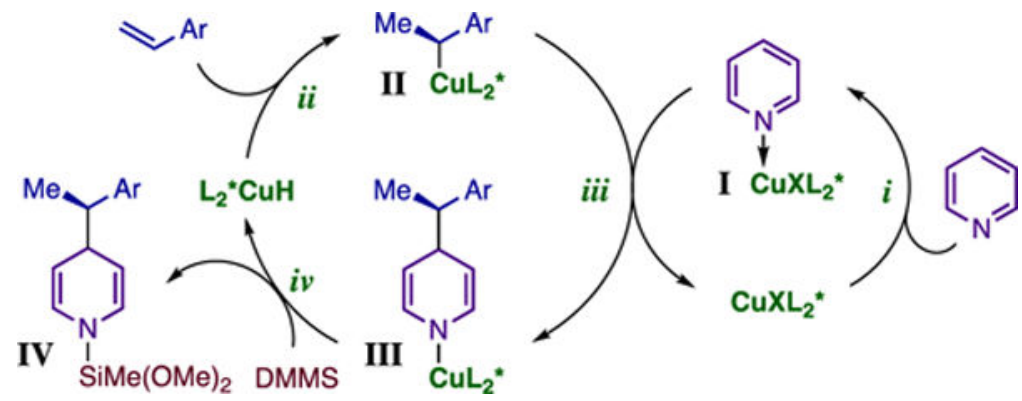

Figure 2.

Plausible Mechanism for the Direct Dearomatization. 
Table 1

Asymmetric Dearomative Syntheses of Functionalized Pyridines (A) and Piperidines (B).

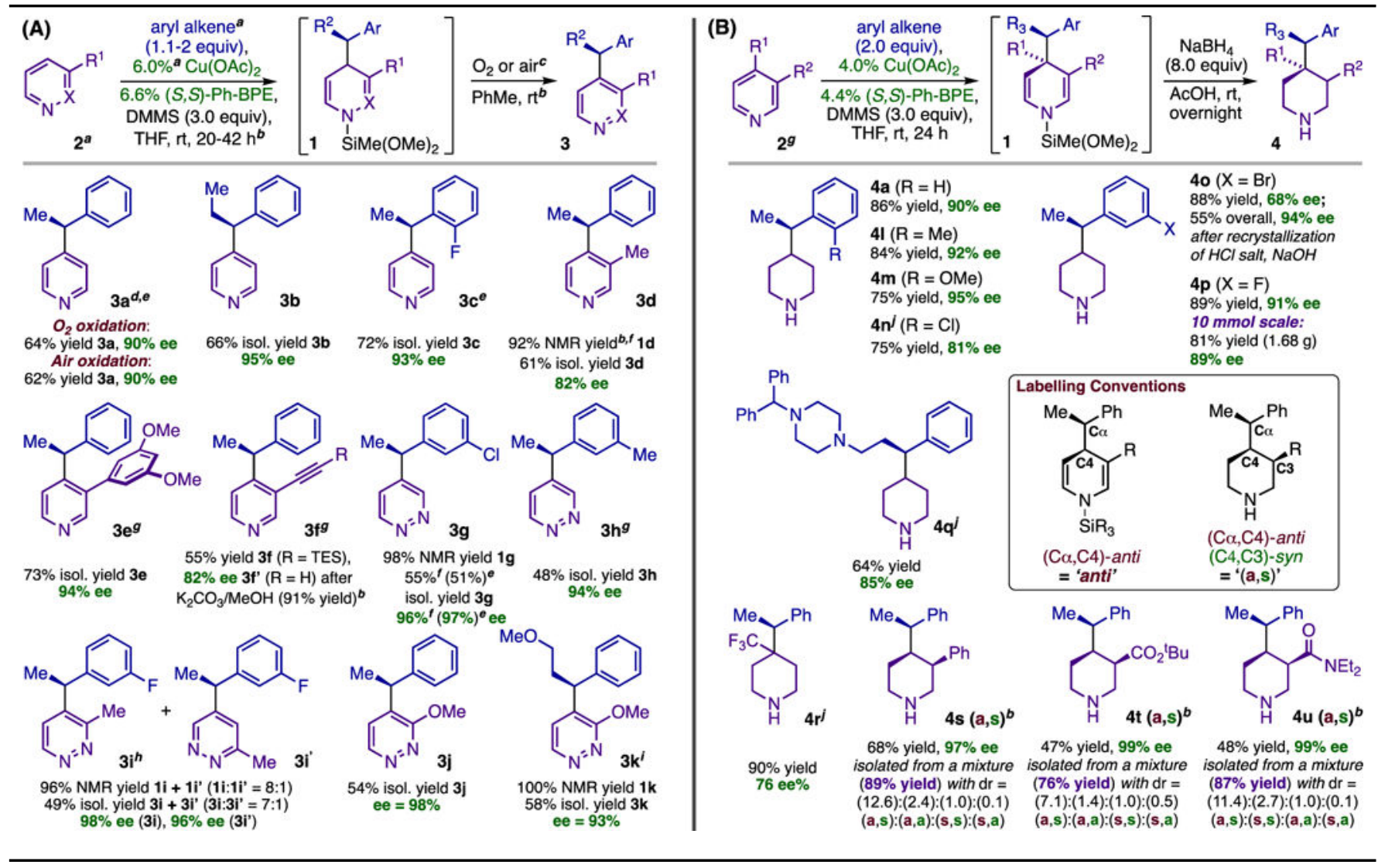

${ }^{a}$ Reactions used 1 mmol 2, 2 equiv olefin except where noted;

$b_{\text {see SI for details; }}$

$c^{c}{ }_{2}$ was used for $\mathbf{3 b}-\mathbf{k}$.;

$d_{\text {yields and ee's are averages for two runs except where noted; }}$

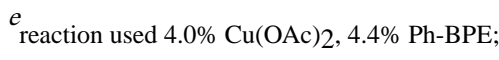

$f$ one measurement;

$g_{\text {used } 0.5 \mathrm{mmol} \mathrm{2} \text {; }}$

$h_{\text {used } 1.5 \text { equiv olefin; }}$

${ }^{i}$ used 1.1 equiv olefin;

$j_{\text {ee determination used the } N \text {-BOC derivative. }}$ 